\title{
Evidence for a Profound Remodeling of Skeletal Muscle and Its Microvasculature in Sickle Cell Anemia
}

\author{
Marion Ravelojaona, ${ }^{*}$ Léonard Féasson, ${ }^{* \dagger}$ Samuel Oyono-Enguéllé, ${ }^{\ddagger}$ Lucile Vincent, ${ }^{\S}$ Ben Djoubairou, ${ }^{\ddagger}$
} Charles Ewa'Sama Essoue, ${ }^{\ddagger}$ and Laurent A. Messonnier

\begin{abstract}
From the Laboratory of Exercise Physiology EA4338, * University of Lyon, Saint Etienne; the Myology Unit - Rhônes-Alpes Reference Center for Rare Neuromuscular Diseases - CHU of Saint Etienne, ${ }^{\dagger}$ Saint Etienne, France; the Laboratory of Physiology, ${ }^{\ddagger}$ Medical School and Biomedical Sciences Faculty, University of Yaounde I, Yaoundé, Cameroon; and the Laboratory of Exercise Physiology EA4338, ${ }^{\S}$ Savoie Mont Blanc University, Chambéry, France
\end{abstract}

Accepted for publication January 23, 2015.

Address correspondence to Laurent A. Messonnier, Ph.D., Laboratoire de Physiologie de l'Exercice EA4338, Université Savoie Mont Blanc, F-73376 Le Bourget-du-Lac Cedex, France. E-mail: laurent. messonnier@univ-savoie.fr.

\begin{abstract}
Sickle cell anemia (SCA) is a hemoglobinopathy leading to major hematologic, hemorheologic, and hemodynamic disorders that induce various complications, including organ failure, and ultimately lead to death. Here, we assessed for the first time repercussions of SCA on skeletal muscle and its microvasculature. Twenty-seven sedentary Cameroonian volunteer men participated in the study. They were assigned to one of three groups according to their hemoglobin status (healthy control subjects, $n=10$; sickle cell trait carriers, $n=10$; and SCA patients, $n=7$ ) and underwent muscle biopsy of the vastus lateralis. SCA was associated with microvessel rarefaction, decrease in capillary tortuosity, and widening of microvessel diameter. The absence of capillary wall reinforcement was shown by lack of wall thickening and lack of fibrous tissue or smooth muscle in their constitution. We also observed changes in fiber type distribution, muscle atrophy, an increase in satellite cell number, and a decrease in activity of creatine kinase and several oxidative enzymes. No signs of tissue necrosis, inflammatory stress, fibrosis, or segmented fibers were observed. The present study highlighted marked effects of SCA on microvascular, structural, and energetic characteristics of skeletal muscle. (Am J Pathol 2015, 185: 1448-1456; http://dx.doi.org/ 10.1016/j.ajpath.2015.01.023)
\end{abstract}

Sickle cell anemia (SCA) is a genetic hemoglobinopathy leading to synthesis of abnormal hemoglobin $(\mathrm{Hb}) \mathrm{S}$. In its deoxygenated form, the mutated hemoglobin polymerizes, giving the red blood cells their particular sickle shape. Because hemolysis related to the fragility of the sickled erythrocytes is not compensated by erythropoiesis, the first clinical manifestation of the disease is severe hemolytic anemia. Sickled red blood cells also display a loss of deformability and an abnormal adhesion to the endothelium that favor the entrapment of erythrocytes in the microvasculature, resulting in vasoocclusive crises $^{1}$ and infarction of vital organs. Resolution of vaso-occlusive episodes amplifies inflammation ${ }^{2-5}$ and oxidative stress ${ }^{4,6}$ that contribute to the pathophysiology of SCA and especially vasculopathy. These vaso-occlusive or vasculopathic phenotypes often result in failure of critical organs such as the spleen, kidneys, liver, brain, lungs, and bones. ${ }^{7}$
Literature related to skeletal muscle in SCA is relatively sparse, maybe because of its less vital nature, but also because sickle myonecrosis episodes are relatively rare complications. ${ }^{8-12}$ However, richly microvascularized and sensitive to hypoxia and anoxia, oxidative stress, and inflammation, skeletal muscle may sustain severe damage from the disease. Occlusion and ischemia-reperfusion episodes are known to induce profound microvascular functional and structural remodeling, including alterations of capillary perfusion ${ }^{4}$ (no reflow phenomena ${ }^{3,5}$ ) and a

\footnotetext{
Supported by grants from the Embassy of France in Cameroon (L.F., L.V. and L.M.), the Région Rhône-Alpes (M.R., L.F., L.V. and L.M.), and the Ministry of Higher Education of Cameroon (S.O.-E.).

M.R. and L.F. contributed equally to this work.

Disclosures: None declared.
} 
Table 1 Anthropometric, Hemoglobinic, and Hematologic Data of the Participants

\begin{tabular}{|c|c|c|c|}
\hline Characteristic & $\mathrm{CON}, n=10$ & $\mathrm{SCT}, n=10$ & $\mathrm{SCA}, n=7$ \\
\hline \multicolumn{4}{|l|}{ Anthropometric data } \\
\hline Age, years & $25 \pm 1$ & $23 \pm 1$ & $24 \pm 2$ \\
\hline Height, $\mathrm{cm}$ & $176 \pm 2$ & $176 \pm 1$ & $171 \pm 3$ \\
\hline Body mass, $\mathrm{kg}$ & $72 \pm 2$ & $68 \pm 2$ & $59 \pm 3 * * * \dagger$ \\
\hline Body fat, $\%$ & $13 \pm 1$ & $11 \pm 1$ & $11 \pm 1$ \\
\hline Body mass index, $\mathrm{kg} / \mathrm{m}^{2}$ & $23.1 \pm 0.6$ & $21.9 \pm 0.4$ & $20.6 \pm 0.8^{* *}$ \\
\hline \multicolumn{4}{|c|}{ Hemoglobinic and hematological data } \\
\hline $\mathrm{HbS}, \%$ & & $31.65 \pm 1.89 * * *$ & $80.90 \pm 2.02 * * * \dagger \dagger \dagger$ \\
\hline $\mathrm{HbF}, \%$ & & $0.08 \pm 0.08$ & $4.63 \pm 1.36^{* * * \dagger \dagger \dagger}$ \\
\hline $\mathrm{Hb}, \mathrm{g} / \mathrm{dL}$ & $14.1 \pm 0.3$ & $13.4 \pm 0.3$ & $8.8 \pm 0.6^{* * * \dagger \dagger \dagger}$ \\
\hline Hct, $\%$ & $41.1 \pm 0.8$ & $39.8 \pm 0.6$ & $25.2 \pm 1.9^{* * * \dagger \dagger \dagger}$ \\
\hline
\end{tabular}

Data are expressed as means \pm SEM.

${ }^{* * P}<0.01,{ }^{* * * P}<0.001$ versus $\mathrm{CON}$.

${ }^{\dagger} P<0.05,{ }^{\dagger \dagger} P<0.001$ versus SCT.

CON, healthy control; Hb, hemoglobin total; HbF, fetal hemoglobin; HbS, hemoglobin S; Hct, hematocrit; SCA, sickle cell anemia; SCT, sickle cell trait.

decrease in capillary density. ${ }^{13}$ Hypoxemia related to anemia and arterial oxyhemoglobin desaturation ${ }^{14,15}$ may induce chronic periods of tissular hypoxia, which has been reported ultimately to depress muscle oxidative capacity via tumor necrosis factor- $\alpha$ and NF- $\kappa \mathrm{B}$ cascades. ${ }^{16,17}$ Furthermore, reperfusion subsequent to ischemia also is known to induce alteration of muscle oxidative phenotype. ${ }^{16}$ From these points of view, changes in muscle energetics can be assumed in patients with SCA. Moreover, ischemia and tissular anoxia related to vaso-occlusive crises potentially may lead to tissue necrosis, ${ }^{3}$ and the proinflammatory state $^{2-5}$ and oxidative stress ${ }^{4,6}$ related to reperfusion subsequent to ischemia also are known to induce muscle atrophy ${ }^{18,19}$ and possibly necrosis., ${ }^{3,20}$ Therefore, even if myonecrosis is not a leading component of sickle crisis, ${ }^{11}$ the major hematologic, hemorheologic, and hemodynamic disorders associated with SCA could lead to a profound remodeling of skeletal muscle and its microvasculature, which could worsen patients' morbidity and loss of autonomy. Because of the lack of knowledge of muscular repercussions of SCA, we studied microvascular, structural, anatomopathological, and energetic characteristics of skeletal muscle in homozygous patients, heterozygous carriers, and control subjects.

\section{Materials and Methods}

\section{Participants}

Twenty-seven sedentary Cameroonian men [healthy control (CON) subjects, $n=10$; sickle cell trait (SCT) carriers, $n=$ 10; and SCA patients, $n=7$ ] participated in this study (Table 1), which took place at the Yaoundé General Hospital (Cameroon). The experiment was approved by the ethics committee (no. 02-06-2007) and conformed to the standards set by the Declaration of Helsinki for human studies. Before giving their written consent, eligible volunteers were informed fully of the objectives, procedures, and possible risks and discomforts related to the protocol.

\section{Inclusion Criteria}

All subjects underwent preliminary screening, including a physical examination and a blood phenotype analysis (Table 1). Volunteers who i) had had a malaria episode within the previous two months; ii) had more than three vaso-occlusive crises per year that required hospitalization ie, displayed a severe clinical phenotype ${ }^{21}$; iii) took any medications; iv) tested positive for HIV; or v) were taking part in another research program were not included in the study.

\section{Muscle Biopsy}

Subjects arrived at the hospital at either $8 \mathrm{AM}$ or noon. Muscle biopsy of the right vastus lateralis was performed percutaneously. ${ }^{22}$ After the patient was shaved, asepsis was attained using alcohol and iso-Betadine 10\% (MEDA Pharma, Paris, France), and local anesthesia of cutaneous and subcutaneous tissues was attained (2\% lidocaine; AstraZeneca, RueilMalmaison, France), without crossing the muscular aponeurosis. A small incision was made until the crossing of the epimysium, through which a Weil-Blakesley forceps (Lawton, Tuttlingen, Germany) was introduced and the sample extracted (approximately 100 to $150 \mathrm{mg}$ ). Part of the biopsy sample was mounted in Cryomount (Histolab, Göteborg, Sweden), then frozen in isopentane (Chevron Phillips Chemicals International, Overijse, Belgium), and finally stored in liquid nitrogen until histochemical and immunohistochemical analyses were performed on $10-\mu \mathrm{m}$ thick serial cryostat transverse sections. The remainder of the sample (frozen and stored in liquid nitrogen) was devoted to enzyme activity analyses.

\section{Microvascular Network Analysis}

Morphometric analysis of microvasculature was performed as done previously. ${ }^{23}$ Briefly, capillaries were identified with CD31 antibody (Dako, Glostrup, Denmark), which recognizes platelet endothelial cell adhesion molecule 1 , expressed by vascular endothelial cells. Capillary wall thickness was measured with 

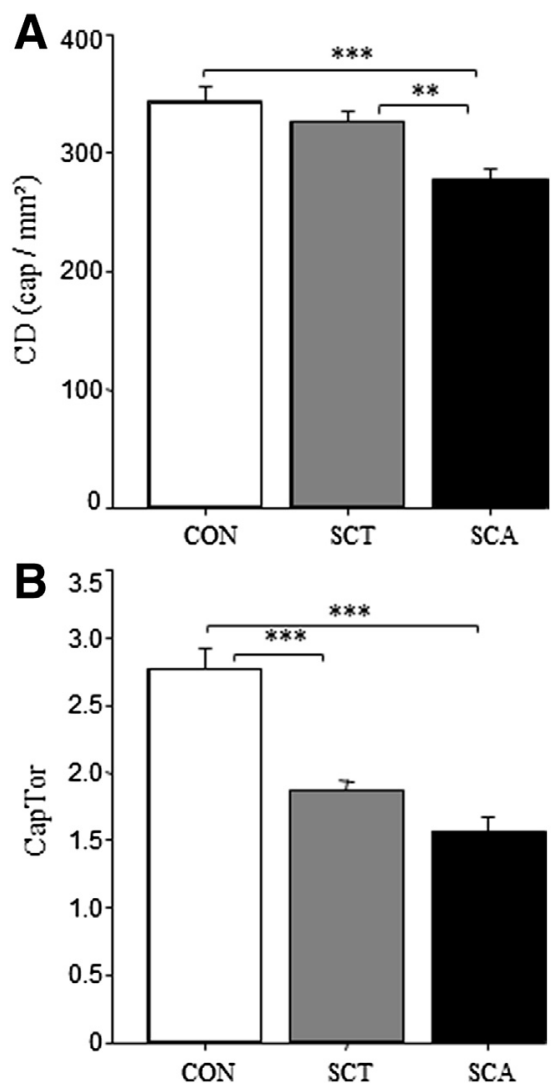

Figure 1 Indices of microvascular network. A: Capillary density (CD), expressed as the number of capillaries per square millimeter. B: Capillary tortuosity (CapTor), measured by means of the following equation: CapTor $=$ capillary surface area $/ \pi(\text { capillary outer diameter } / 2)^{2}$. CON, healthy control; SCA, sickle cell anemia; SCT, sickle cell trait. ${ }^{* *} P<0.01,{ }^{* * *} P<0.001$.

hematoxylin-eosin-safran staining. The presence of smooth muscle myosin heavy chain and fibrous or collagenous tissue was determined by means of immunofluorescence (double staining CD31 and smooth muscle myosin heavy chain, Abcam, Cambridge, UK) and Van Gieson staining, ${ }^{24}$ respectively.

\section{Muscle Characteristics}

Fiber type determination, distribution, and morphology were analyzed as previously described. ${ }^{25}$ Fiber type was determined on immunohistochemical preparations by using anti-fast IIa myosin heavy chain N2.261 (Alexis Biochemicals, San Diego, CA) and anti-slow myosin heavy chain A4.951 (Alexis Biochemicals) monoclonal antibodies. The fiber types were designated as I, I-IIa, IIa, IIa-IIx, and IIx (previously referred to as IIb by Brooke and Kaiser $\left.^{26}\right){ }^{25,27}$ Hematoxylin-eosin-safran staining enabled evaluation of common muscle remodeling signs such as necrotic fibers, fibrosis, fat cells, inflammation signs, internalized nuclei, and segmented fibers. Major histocompatibility complex I also was used to look for inflammation. ${ }^{24}$ Counts of regenerated fibers and neofibers and satellite cells were performed using monoclonal antibody CD56 (Dako) with Mayer hematoxylin counterstaining allowing visualization of nuclei. ${ }^{28}$

\section{Enzyme Activities}

Creatine kinase, phosphofructokinase, lactate dehydrogenase, citrate synthase, and $\beta$-hydroxyacyl-CoA dehydrogenase activities were measured at $25^{\circ} \mathrm{C}$. Cytochrome $c$ oxidase (COX) assessment per fiber type was performed as previously described using SigmaScan Pro (SPSS, Chicago, IL). ${ }^{25}$ Optical density for each muscle fiber was determined using SigmaScan Pro to measure COX intensity. For each subject, a single value per fiber type was obtained by averaging measurements from approximately 60 well-identified muscle fibers.

\section{Microscopy and Analysis}

Muscle sections were viewed and analyzed under a light microscope (DM2000; Leica Microsystems, Wetzlar, Germany) connected to a digital camera (DFC490, Leica). Images were analyzed by an investigator (M.R.) blinded to the nature of the samples by using SigmaScan Pro. ${ }^{23,25}$

\section{Statistical Analysis}

Descriptive statistics are expressed as means \pm SEM. When the one-way analysis of variance revealed an $\mathrm{HbS}$ effect (see Results), Fisher post hoc tests were used to compare the three groups (see Results). Differences were considered to

Table 2 Microvascular Remodeling in Healthy Control, Sickle Cell Anemia, and Sickle Cell Trait Muscle

\begin{tabular}{lccc}
\hline Microvascular characteristic & CON, $n=10$ & SCT, $n=10$ & SCA, $n=7$ \\
\hline Number of capillaries per fiber & $4.68 \pm 0.21$ & $4.15 \pm 0.22$ & $2.53 \pm 0.11^{* * * \dagger \dagger \dagger}$ \\
Capillary surface area, $\mu \mathrm{m}^{2}$ & $45.6 \pm 2.5$ & $43.2 \pm 1.8$ & $65.4 \pm 7.0^{* * \dagger \dagger \dagger}$ \\
$\mathrm{CD} \times \mathrm{CSA}^{\ddagger}$ & $15,573 \pm 878$ & $13,897 \pm 616$ & $18,010 \pm 1590^{\dagger \dagger}$ \\
$\mathrm{LC} / \mathrm{PF}, \%^{\S}$ & $14.49 \pm 0.82$ & $13.50 \pm 0.86$ & $15.88 \pm 0.76$ \\
Capillary wall thickness, $\mu \mathrm{m}$ & $0.50 \pm 0.02$ & $0.50 \pm 0.02$ & $0.44 \pm 0.03$ \\
Capillary wall thickness/COD, $\mu \mathrm{m}$ & $0.119 \pm 0.010$ & $0.092 \pm 0.006^{*}$ & $0.061 \pm 0.007^{* * * \dagger}$ \\
\hline
\end{tabular}

Values are means \pm SEM.

${ }^{*} P<0.05,{ }^{* *} P<0.01$, and ${ }^{* * *} P<0.001$ versus CON.

${ }^{\dagger} P<0.05,{ }^{\dagger \dagger} P<0.01$, and ${ }^{\dagger \dagger \dagger} P<0.001$ versus SCT.

${ }^{\ddagger} \mathrm{CD} \times$ CSA: capillary density $\times$ capillary surface area, to estimate instantaneous blood volume in a $10-\mu \mathrm{m}$ thick slice.

${ }^{\S} \mathrm{LC} / \mathrm{PF}$ : length of capillaries in contact with a fiber over the perimeter of the fiber, to estimate the functional surface of exchange.

COD, capillary outer diameter; CON, healthy control; SCA, sickle cell anemia; SCT, sickle cell trait. 
be significant for $P<0.05$ and to represent a tendency for $0.05 \leq P<0.1$.

\section{Results}

\section{Microvascular Remodeling}

SCA was associated with decreased capillary density $(P=0.0012)$ (Figure 1A) and number of capillaries in contact with a fiber $(P<0.0001)$ (Table 2$)$. The estimated blood volume in the $10-\mu \mathrm{m}$ slice was unaffected by $\mathrm{HbS}$ (Table 2), which is due to the increase of the capillary surface area in patients $(P=0.0009)$ (Table 2$)$. Capillary tortuosity was lower in SCA patients $(P<0.0001)$ (Figure $1 \mathrm{~B})$, whereas the length of capillaries in contact with a fiber over the perimeter of the fiber was not affected (Table 2). Capillary outer diameter increased strikingly with $\mathrm{HbS}(P<0.0001)$ (Figure 2A) so that the percentage (Figure 2B) and number (Figure 2C) of wide microvessels $(>10 \mu \mathrm{m})$ increased $(P<0.0001$ for both), whereas the percentage (Figure $2 \mathrm{~B})$ and number (Figure 2C) of narrow capillaries $(<5 \mu \mathrm{m})$ decreased $(P<0.0001$ and $P=0.0003$, respectively) in SCT carriers and decreased further in SCA patients compared with CON subjects.

Immunofluorescence [double staining endothelial cells (CD31) + smooth muscle (smooth muscle myosin heavy chain)] and histochemical (Van Gieson stain) analyses did not reveal the presence of either smooth muscle (Figure 3A) or fibrous or collagenous tissue (Figure 3B) around the studied capillaries. Microvessel wall thickness was not different among the three groups, but it tended to be thinner in patients than in carriers and CONs ( $P=0.0813$ and $P=0.0909$, respectively) (Table 2). The ratio of capillary wall thickness over capillary outer diameter decreased as a function of $\mathrm{HbS}$ percentage $(P=0.0003)$ (Table 2).

\section{Skeletal Muscle Remodeling}

Percentage of type I fibers increased in patients $(P=0.0335)$, whereas percentages of type IIa and IIa-IIx fibers were lower ( $P=0.0255$ and $P=0.0482$, respectively). No difference was found among the groups concerning distribution of type I-IIa and IIx fibers (Figure 4A). The mean surface areas of type I and IIa fibers decreased in patients $(P=0.0045$ and $P=0.0029$, respectively). Mean surface area of type IIx and hybrid (I-IIa and IIa-IIx) fibers did not differ among the groups (Figure 4B). Surface area for 100 myocytes (taking into account fiber type distribution) demonstrated clear amyotrophy in patients $(P=0.0130)$ (Figure 4C).

In terms of degenerative signs, more interfascicular adipocytes were observed in patients $(P=0.0160)$. However, no differences were observed among the three groups in term of tissue necrosis and inflammatory infiltrate. Concerning regenerative signs, a higher number of internalized nuclei was found in carriers than in patients $(P=0.0193)$ and CONs $(P=0.0110)$, with no difference between the
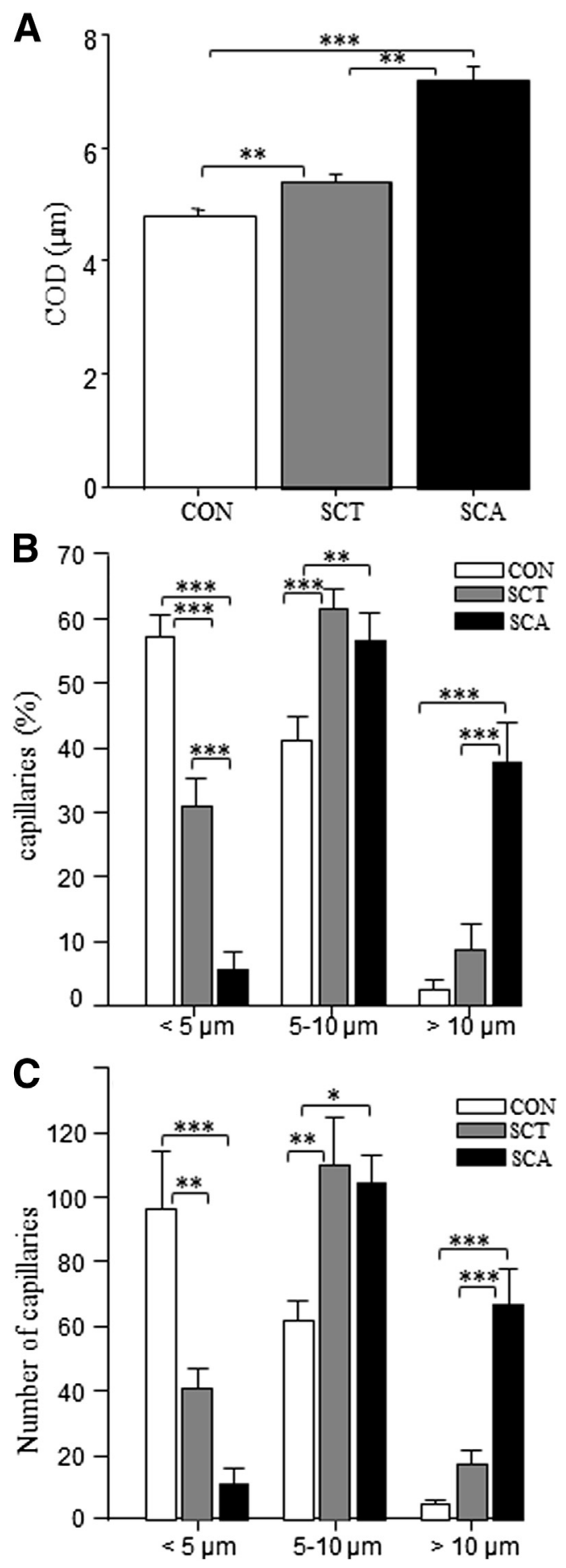

Figure 2 Capillary outer diameter (COD). A: Mean COD. B: Percentage of capillaries with COD less than $5 \mu \mathrm{m}, 5$ to $10 \mu \mathrm{m}$, and greater than $10 \mu \mathrm{m}$. C: Number of capillaries with COD less than $5 \mu \mathrm{m}, 5$ to $10 \mu \mathrm{m}$, and greater than $10 \mu \mathrm{m}$. CON, healthy control; SCA, sickle cell anemia; SCT, sickle cell trait. ${ }^{*} P<0.05,{ }^{* *} P<0.01$, and ${ }^{* * *} P<0.001$.

two latter groups. A higher number of satellite cells per 100 muscle fibers was found with $\mathrm{HbS}(P<0.0001)$ (Table 3).

Creatine kinase $(P=0.0147)$, citrate synthase $(P<0.0001)$, and $\beta$-hydroxyacyl-CoA dehydrogenase $(P=0.0012)$ activities were lower in patients. COX 

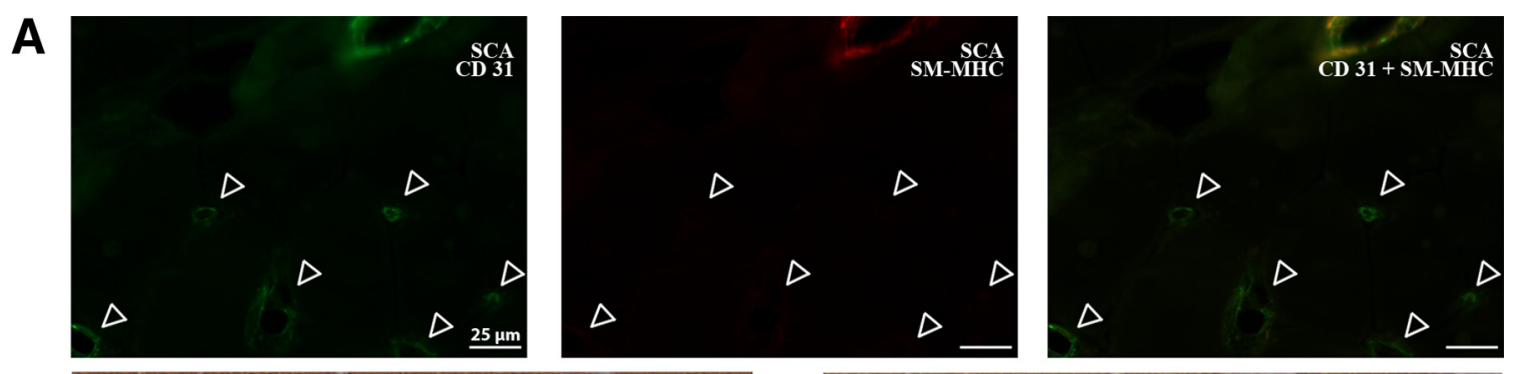

B
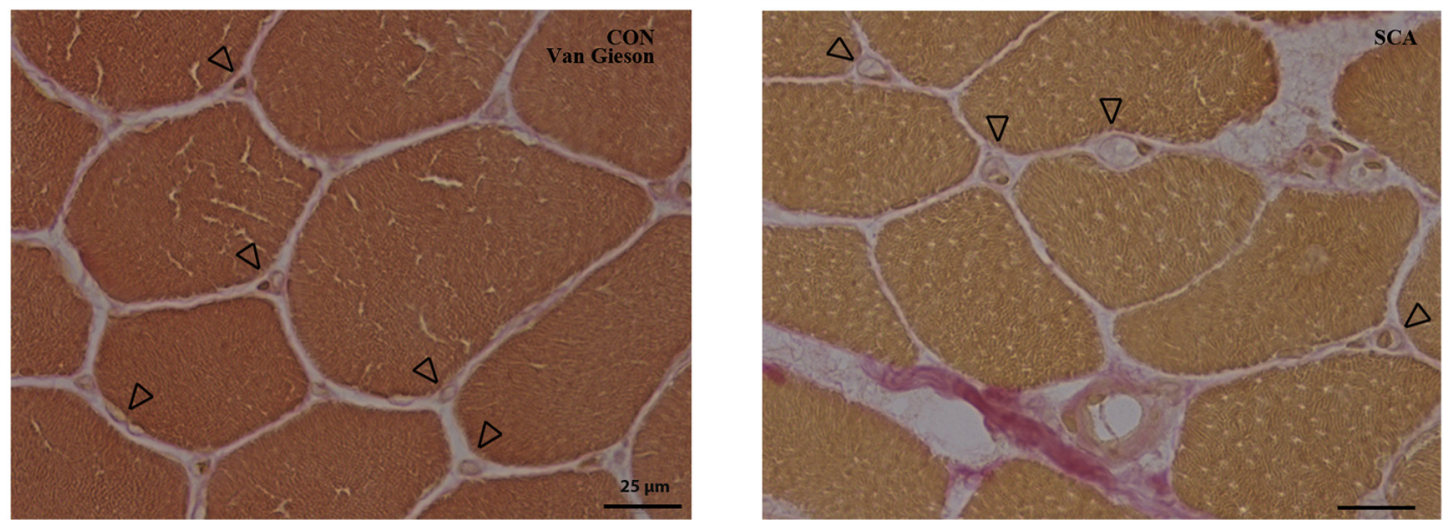

Figure 3 Structure of capillary walls. A: Double immunofluorescence staining showing capillaries (CD31) in green and smooth muscle myosin heavy chain $(\mathrm{SM}-\mathrm{MHC})$ in red. B: Van Gieson stain showing fibrous and collagenous tissue. Arrowheads indicate capillaries $(\mathbf{A}$ and B). Original magnification: $\times 400$. CON, healthy control; SCA, sickle cell anemia.

activity in IIa and IIx fibers was lower $(P=0.0691$ and $P=0.0291$, respectively) in patients. Phosphofructokinase and lactate dehydrogenase activities were not different among groups (Table 3).

\section{Discussion}

The present study highlighted marked effects of SCA on microvascular, structural, and energetic characteristics of skeletal muscle.

The lower capillary density (Figure 1A) and number of capillaries in contact with a muscle fiber (Table 2) underline an important rarefaction of the microvascular network within the skeletal muscle of SCA patients. The observed reduction in the microvascular network might be explained by an endothelial apoptosis (caused by lumen obstruction or absence of reflow after resolution of ischemia ${ }^{3,29}$ ) unbalanced by compensatory angiogenic processes.

At first sight, lower capillary density and number of capillaries per fiber collectively would suggest disturbances in blood supply to muscular tissue and exchange surface area between capillaries and adjacent muscle fibers. Both of these potentially could reduce gas and metabolite supply to (eg, oxygen and glucose) and release from (eg, carbon dioxide and lactate) tissues. However, the functional surface of exchange between a muscle fiber and the adjacent microvessels (length of capillaries in contact with a fiber over the perimeter of the fiber index) was not different in patients (Table 2).
The maintenance of this functional surface of exchange was explained mainly by lower fiber surface area ie, amyotrophy in patients (vide infra). Likewise, the estimated blood volume that crosses the muscle section (capillary density $\times$ capillary surface area index $)^{23}$ was not different in patients than in CONs (Table 2). Hence, despite a lower capillary density, muscle blood supply might not be altered in SCA, suggesting that the lower oxygen supply to tissue reported in patients ${ }^{30,31}$ could be attributed to anemia and arterial oxygen desaturation ${ }^{15,32}$ rather than to impaired local blood supply. This inference is in accordance with previous results showing reduced microvascular oxygenation in SCA patients; however, the microvascular blood flow actually increased in that study. ${ }^{31}$ Mean capillary outer diameter was bigger in patients $(8.6 \mu \mathrm{m})$, approaching the mean diameter of erythrocytes (Figure 2A). This enlargement of microvessels in SCA may facilitate passage of the less deformable $\mathrm{HbS}$-containing erythrocytes through the capillary network, ${ }^{33}$ dampening the risks of their entrapment in the microvasculature ${ }^{34}$ and reducing (but not completely stopping) the associated local blood flow disorders. ${ }^{35}$ Furthermore, wider microvessels may contribute to reducing plasma skimming, improving capillary recruitment by erythrocytes, and ameliorating oxygen supply to tissues. Moreover, the lower capillary tortuosity observed in SCA patients may, by shortening erythrocyte transit time in the microvasculature, also contribute to smoothing local blood flow disorders in SCA (Figure 1B). This apparent protective mechanism against blood flow disorders mediated by wider capillaries and a decreased capillary tortuosity 

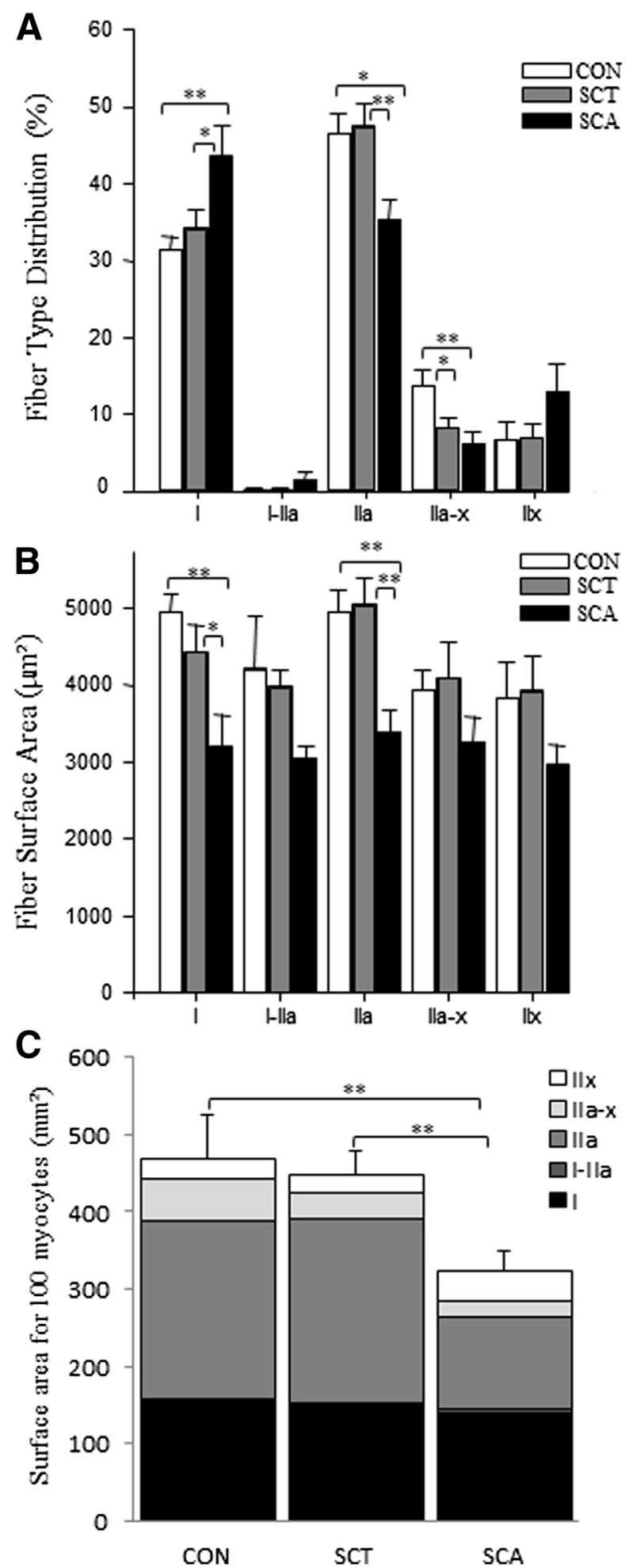

Figure 4 Fiber type distribution (A), fiber surface area (B), and index of amyotrophy, with representative surface area for 100 myocytes taking into account fiber type distribution (C). CON, healthy control; SCA, sickle cell anemia; SCT, sickle cell trait. ${ }^{*} P<0.05,{ }^{*} P<0.01$.

may explain, at least to some extent, the fact that myonecrosis is not a leading component of sickle crisis. ${ }^{9}$

These particular adaptations of the microvasculature may be attributed to i) regression of the narrowest microvessels, ii) arterialization of some capillaries, iii) thickening of the capillary wall of the existing microvessels, iv) enlargement of their lumen, v) neovascularization, vi) bridging of the stenosis area with bypasses that are enlarged collateral blood vessels, or vii) combination of all aforementioned possibilities. ${ }^{36}$ Several results of the present study are informative regarding these different possibilities.

Figure 2, B and C shows clearly that both percentage and number of the narrowest $(<5 \mu \mathrm{m})$ and widest $(>10 \mu \mathrm{m})$ microvessels were, respectively, lower and higher in SCA, suggesting a regression of the narrowest microvessels. We tested the presence of smooth muscle and fibrous or collagenous tissue around the observed microvessels, and results for both were negative (Figure 3). These latter results exclude the hypothesis that the observed microvessels were terminal arterioles or primary venules, but they support the fact that enlarged capillaries were observed. Because capillary wall thickness was not different among the three groups, the wider size of the capillaries, therefore, can be attributed to an enlargement of the lumen. Finally, the lower ratio of capillary wall thickness over outer diameter observed with HbS showed distension of the capillaries in SCA (Table 2). Whether this distension can be related to a decrease in peripheral resistance and to the lower arterial blood pressure observed in $\mathrm{SCA}^{37-39}$ remains to be investigated.

Taken together, the absence of smooth muscle and fibrous or collagenous tissue, the lack of capillary wall thickening, and the distension of the capillaries argue in favor of a weakening of the capillary structure in SCA. It is tempting to relate this apparent distension and fragility of the microvessels to the hemorrhagic cerebrovascular accidents occurring without aneurysms that are observed in SCA patients. ${ }^{8,40,41}$ The severity of microvascular remodeling also was closely associated with $\mathrm{HbS}$ proportion. Although considered asymptomatic, SCT carriers display significant microvascular remodeling, which was intermediary to the remodeling observed in CON subjects and SCA patients.

The 30\% smaller type I and IIa fiber surface areas, along with the lower mean surface area covered by 100 myocytes (taking into account fiber type distribution), clearly demonstrate significant amyotrophy in patients compared with carriers and CONs (Figure 4, B and C). Although the carriers and CONs displayed concordant muscle fiber type distribution with those reported in other African populations, ${ }^{25,42}$ patients exhibited a higher proportion of type I and a lower proportion of type IIa muscle fibers (Figure 4A). This particular muscle fiber type distribution seems to suggest a disappearance of type IIa and a relative maintenance of type I muscle fibers.

The low physical activity level and energy expenditure of SCA patients during everyday life may not require type II muscle fiber recruitment, but it involves mainly type I muscle fibers that might help maintenance of this latter muscle fiber type. The general amyotrophy is concordant with the repeated, sometimes silent or subclinical muscle vaso-occlusions and ischemia-reperfusion periods experienced by SCA patients ${ }^{2,5,43}$ that are known 
Table 3 Muscle Structural, Pathophysiological, and Energetic Characteristics

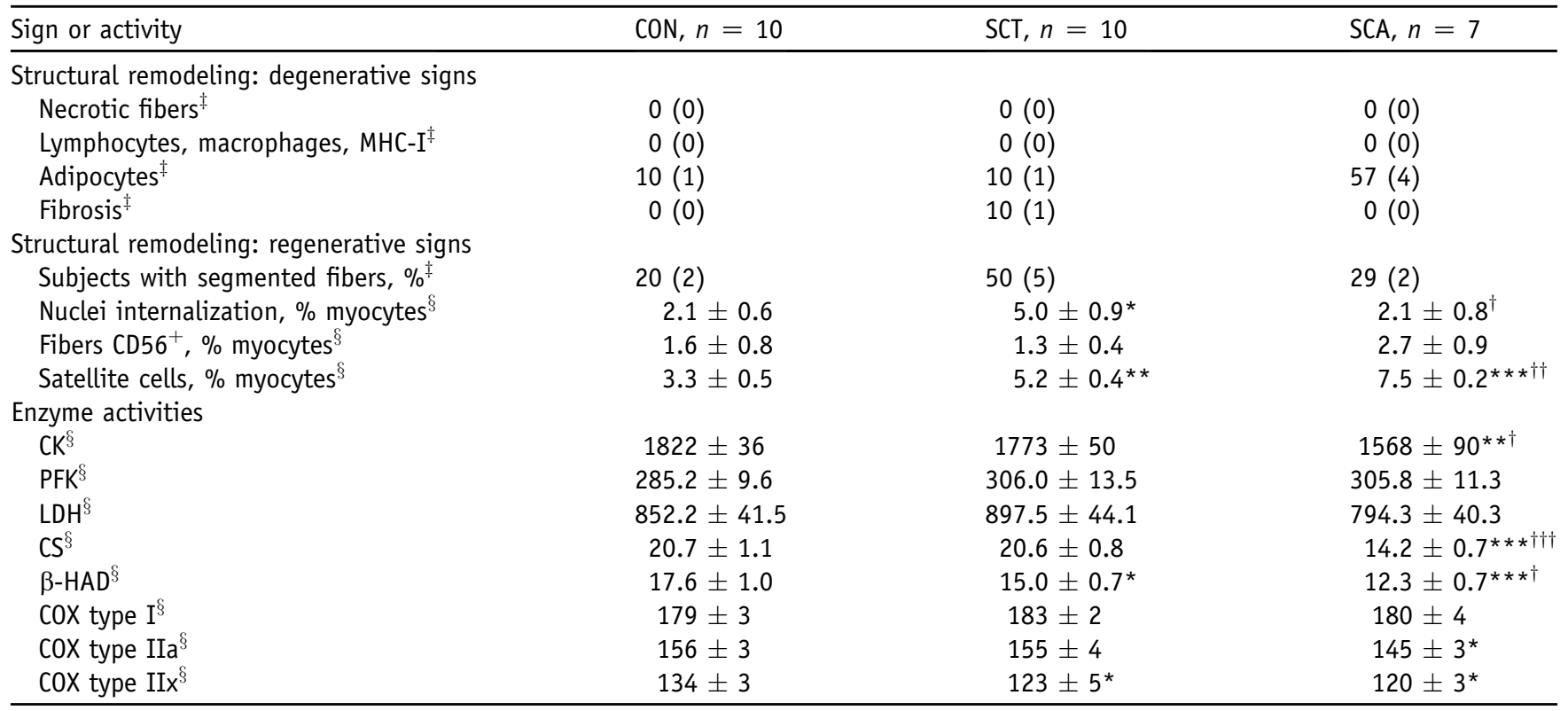

For enzyme activities, values are expressed for all activities as $\mu \mathrm{mol} \cdot \min ^{-1} \cdot \mathrm{g}^{-1}$ dry muscle except for COX activity, which is expressed in arbitrary units. ${ }^{*} P<0.05,{ }^{*} P P<0.01$, and $* * * P<0.001$ versus CON.

${ }^{\dagger} P<0.05,{ }^{\dagger \dagger} P<0.01$, and ${ }^{\dagger \dagger \dagger} P<0.001$ versus SCT.

ॠValues are percentage of subjects showing histologic signs (number of subjects).

${ }^{\S}$ Values are expressed as means \pm SEM.

$\beta$-HAD, $\beta$-hydroxyacyl-CoA dehydrogenase; CK, creatine kinase; CON, healthy control; COX, cytochrome $c$ oxidase; CS, citrate synthase; LDH, lactate dehydrogenase; MHC-I, major histocompatibility complex I; PFK, phosphofructokinase; SCA, sickle cell anemia; SCT, sickle cell trait.

to induce skeletal muscle dysfunction and eventually tissue necrosis. $^{3}$

Several other signs also showed significant muscle remodeling in SCA patients (Table 3). Four of the seven patients displayed intercellular adipocytes, which is a sign of muscle degeneration ${ }^{24}$ that reinforces the hypothesis of muscle wasting reported in Skeletal Muscle Remodeling. The higher number of satellite cells in patients and carriers (proportionally to $\mathrm{HbS}$ content) suggests a proliferation of those cells and an activation of regenerative processes ${ }^{28}$ that might be interpreted as an attempt of the myocytes to counteract muscle wasting. However, nuclei internalization and segmented fibers, other witnesses of actual regeneration, ${ }^{24}$ were higher in carriers and not significantly up-regulated in patients. In the aggregate, the present results seem to indicate that if regeneration was activated in carriers and patients, this process did not seem to occur effectively in patients, which at least partly might explain why muscle wasting appeared in patients and not in carriers. In other words, if the amyotrophy observed in SCA patients is related partly to their physical hypoactivity, ${ }^{10,44}$ a default in muscle regeneration cannot be excluded totally. No fibrosis and no signs of inflammation, such as lymphocytes, macrophages, or fibers expressing major histocompatibility complex I, were observed in patients, which is not divergent from previous studies' results showing myonecrosis secondary to sickle crises with minimal inflammatory reaction. ${ }^{9,11}$ Hence, skeletal muscle appears to be relatively resistant to disorders associated with SCA (eg, ischemic tissue injury), which also might explain, at least partly, why myonecrosis is not a leading component of the sickle crisis.

Analysis of key enzyme activities of energetic metabolism revealed decreased $\beta$-hydroxyacyl-CoA dehydrogenase and citrate synthase activities in SCA patients (Table 3). Because these enzymes are good markers of fatty acid oxidation and the Krebs cycle, their lower activity levels depict an overall impairment of muscle oxidative capacity, which was confirmed by the decreased COX activity obtained in type IIa and IIx fibers (Table 3). The fact that activity of this latter enzyme was maintained in type I fibers was reminiscent of our above-mentioned results concerning muscle fiber type distribution. Muscle creatine kinase activity also was reduced in patients (Table 3). Because muscle creatine kinase and COX activities are depressed by reactive oxygen species, ${ }^{45,46}$ oxidative stress (well known in the vascular bed ${ }^{35}$ but unknown in the muscle compartment) might be suspected in skeletal muscle in SCA patients. However, this hypothesis remains to be tested. Together, amyotrophy and altered oxidative capacity may explain poor muscle function; impaired exercise tolerance; and, consequently, the low quality of life reported in SCA patients. ${ }^{47,48}$

\section{Conclusion}

In summary, the present study highlighted for the first time a profound remodeling of microvascular, structural, and energetic characteristics of skeletal muscle in SCA patients and, to a 
lesser extent, in SCT carriers. The microvascular remodeling included microvessel rarefaction, lower capillary tortuosity, and striking lumen enlargement. However, no reinforcement of the capillary wall was apparent. Although no signs of tissue necrosis, inflammatory stress, fibrosis, or segmented fibers were noticed, an alteration in fiber type distribution, a significant amyotrophy affecting mainly type I and IIa muscle fibers, and a marked decrease in muscle oxidative capacity were observed.

\section{Acknowledgments}

We thank Marie-Pierre Blanc, Amandine Delet, Anne Gourounas, Dominique Gouttefangeas (University of Lyon, Laboratory of Exercise Physiology EA4338, Saint Etienne, France), Jean-Pierre Lamarque, François-Xavier Owona, Philippe Stoft, and Patrice Thiriet for helpful technical assistance and the Institut National de la Jeunesse et des Sports of Yaoundé, the Ministry of Higher Education of Cameroon, the Embassy of France in Cameroon, and Les Brasseries du Cameroun for logistic support.

\section{References}

1. Serjeant G: Sickle Cell Disease. ed 2. Oxford, Oxford University Press, 1992

2. Nath KA, Grande JP, Croatt AJ, Frank E, Caplice NM, Hebbel RP, Katusic ZS: Transgenic sickle mice are markedly sensitive to renal ischemia-reperfusion injury. Am J Pathol 2005, 166:963-972

3. Gute DC, Ishida T, Yarimizu K, Korthuis RJ: Inflammatory responses to ischemia and reperfusion in skeletal muscle. Mol Cell Biochem 1998, 179:169-187

4. Carden DL, Granger DN: Pathophysiology of ischaemia-reperfusion injury. J Pathol 2000, 190:255-266

5. Eltzschig HK, Eckle T: Ischemia and reperfusion-from mechanism to translation. Nat Med 2011, 17:1391-1401

6. Chirico EN, Pialoux V: Role of oxidative stress in the pathogenesis of sickle cell disease. IUBMB Life 2012, 64:72-80

7. Gladwin MT, Sachdev V: Cardiovascular abnormalities in sickle cell disease. J Am Coll Cardiol 2012, 59:1123-1133

8. Vicari P, Choairy AC, Siufi GC, Arantes AM, Fonseca JR, Figueiredo MS: Embolization of intracranial aneurysms and sickle cell disease. Am J Hematol 2004, 76:83-84

9. Valeriano-Marcet J, Kerr LD: Myonecrosis and myofibrosis as complications of sickle cell anemia. Ann Intern Med 1991, 115:99-101

10. Schumacher HR Jr, Murray WM, Dalinka MK: Acute muscle injury complicating sickle cell crisis. Semin Arthritis Rheum 1990, 19:243-247

11. Mani S, Duffy TP: Sickle myonecrosis revisited. Am J Med 1993, 95: $525-530$

12. Malekgoudarzi B, Feffer S: Myonecrosis in sickle cell anemia. N Engl J Med 1999, 340:483

13. Kawada S, Ishii N: Changes in skeletal muscle size, fibre-type composition and capillary supply after chronic venous occlusion in rats. Acta Physiol (Oxf) 2008, 192:541-549

14. Setty BN, Stuart MJ, Dampier C, Brodecki D, Allen JL: Hypoxaemia in sickle cell disease: biomarker modulation and relevance to pathophysiology. Lancet 2003, 362:1450-1455

15. Quinn CT, Sargent JW: Daytime steady-state haemoglobin desaturation is a risk factor for overt stroke in children with sickle cell anaemia. Br J Haematol 2008, 140:336-339

16. Remels AH, Gosker HR, Schrauwen P, Hommelberg PP, Sliwinski P, Polkey M, Galdiz J, Wouters EF, Langen RC, Schols AM: TNF-alpha impairs regulation of muscle oxidative phenotype: implications for cachexia? FASEB J 2010, 24:5052-5062

17. de Theije C, Costes F, Langen RC, Pison C, Gosker HR: Hypoxia and muscle maintenance regulation: implications for chronic respiratory disease. Curr Opin Clin Nutr Metab Care 2011, 14:548-553

18. Kondo H, Miura M, Itokawa Y: Oxidative stress in skeletal muscle atrophied by immobilization. Acta Physiol Scand 1991, 142:527-528

19. Powers SK, Jackson MJ: Exercise-induced oxidative stress: cellular mechanisms and impact on muscle force production. Physiol Rev 2008, 88:1243-1276

20. Ejindu VC, Hine AL, Mashayekhi M, Shorvon PJ, Misra RR: Musculoskeletal manifestations of sickle cell disease. Radiographics 2007, 27:1005-1021

21. Platt OS, Thorington BD, Brambilla DJ, Milner PF, Rosse WF, Vichinsky E, Kinney TR: Pain in sickle cell disease. Rates and risk factors. N Engl J Med 1991, 325:11-16

22. Féasson L, Stockholm D, Freyssenet D, Richard I, Duguez S, Beckmann JS, Denis C: Molecular adaptations of neuromuscular disease-associated proteins in response to eccentric exercise in human skeletal muscle. J Physiol 2002, 543:297-306

23. Vincent L, Féasson L, Oyono-Enguéllé S, Banimbek V, Denis C, Guarneri C, Aufradet E, Monchanin G, Martin C, Gozal D, Dohbobga M, Wouassi D, Garet M, Thiriet P, Messonnier L: Remodeling of skeletal muscle microvasculature in sickle cell trait and alpha-thalassemia. Am J Physiol Heart Circ Physiol 2010, 298:H375-H384

24. Dubowitz V, Sewry CA, Lane R: Muscle Biopsy: A Practical Approach. 3rd ed. Philadelphia, Saunders Elsevier, 2007

25. Vincent L, Féasson L, Oyono-Enguéllé S, Banimbek V, Monchanin G, Dohbobga M, Wouassi D, Martin C, Gozal D, Geyssant A, Thiriet P, Denis C, Messonnier L: Skeletal muscle structural and energetic characteristics in subjects with sickle cell trait, alpha-thalassemia, or dual hemoglobinopathy. J Appl Physiol (1985) 2010, 109:728-734

26. Brooke MH, Kaiser KK: Muscle fiber types: how many and what kind? Arch Neurol 1970, 23:369-379

27. Verney J, Kadi F, Charifi N, Féasson L, Saafi MA, Castells J, PiehlAulin K, Denis C: Effects of combined lower body endurance and upper body resistance training on the satellite cell pool in elderly subjects. Muscle Nerve 2008, 38:1147-1154

28. Kadi F, Schjerling P, Andersen LL, Charifi N, Madsen JL, Christensen LR, Andersen JL: The effects of heavy resistance training and detraining on satellite cells in human skeletal muscles. J Physiol 2004, 558:1005-1012

29. Carmeliet P: Mechanisms of angiogenesis and arteriogenesis. Nat Med 2000, 6:389-395

30. Nahavandi M, Tavakkoli F, Hasan SP, Wyche MQ, Castro O: Cerebral oximetry in patients with sickle cell disease. Eur J Clin Invest 2004, 34:143-148

31. Waltz X, Pichon A, Lemonne N, Mougenel D, Lalanne-Mistrih ML, Lamarre Y, Tarer V, Tressières B, Etienne-Julan M, HardyDessources MD, Hue O, Connes P: Normal muscle oxygen consumption and fatigability in sickle cell patients despite reduced microvascular oxygenation and hemorheological abnormalities. PLoS One 2012, 7:e52471

32. Quinn CT, Variste J, Dowling MM: Haemoglobin oxygen saturation is a determinant of cerebral artery blood flow velocity in children with sickle cell anaemia. Br J Haematol 2009, 145:500-505

33. Parthasarathi K, Lipowsky HH: Capillary recruitment in response to tissue hypoxia and its dependence on red blood cell deformability. Am J Physiol 1999, 277:H2145-H2157

34. Simchon S, Jan KM, Chien S: Influence of reduced red cell deformability on regional blood flow. Am J Physiol 1987, 253:H898-H903

35. Rees DC, Williams TN, Gladwin MT: Sickle-cell disease. Lancet 2010, 376:2018-2031

36. Hudlicka O, Brown M, Egginton S: Angiogenesis in skeletal and cardiac muscle. Physiol Rev 1992, 72:369-417

37. Grell GA, Alleyne GA, Serjeant GR: Blood pressure in adults with homozygous sickle cell disease. Lancet 1981, 2:1166 
38. Homi J, Homi-Levee L, Gentles S, Thomas P, Serjeant G: Adolescent blood pressure in a cohort study of sickle cell disease. Arch Intern Med 1993, 153:1233-1236

39. Pegelow CH, Colangelo L, Steinberg M, Wright EC, Smith J, Phillips G, Vichinsky E: Natural history of blood pressure in sickle cell disease: risks for stroke and death associated with relative hypertension in sickle cell anemia. Am J Med 1997, 102:171-177

40. Ohene-Frempong K, Weiner SJ, Sleeper LA, Miller ST, Embury S, Moohr JW, Wethers DL, Pegelow CH, Gill FM: Cerebrovascular accidents in sickle cell disease: rates and risk factors. Blood 1998, 91:288-294

41. Powars D, Wilson B, Imbus C, Pegelow C, Allen J: The natural history of stroke in sickle cell disease. Am J Med 1978, 65:461-471

42. Ama PF, Simoneau JA, Boulay MR, Serresse O, Thériault G, Bouchard C: Skeletal muscle characteristics in sedentary black and Caucasian males. J Appl Physiol (1985) 1986, 61:1758-1761

43. Wallace KL, Marshall MA, Ramos SI, Lannigan JA, Field JJ, Strieter RM, Linden J: NKT cells mediate pulmonary inflammation and dysfunction in murine sickle cell disease through production of IFN-gamma and CXCR3 chemokines. Blood 2009, 114:667-676
44. Buchowski MS, Townsend KM, Williams R, Chen KY: Patterns and energy expenditure of free-living physical activity in adolescents with sickle cell anemia. J Pediatr 2002, 140:86-92

45. Di Giovanni S, Mirabella M, Papacci M, Odoardi F, Silvestri G, Servidei S: Apoptosis and ROS detoxification enzymes correlate with cytochrome c oxidase deficiency in mitochondrial encephalomyopathies. Mol Cell Neurosci 2001, 17:696-705

46. Genet S, Kale RK, Baquer NZ: Effects of free radicals on cytosolic creatine kinase activities and protection by antioxidant enzymes and sulfhydryl compounds. Mol Cell Biochem 2000, 210: $23-28$

47. Callahan LA, Woods KF, Mensah GA, Ramsey LT, Barbeau P, Gutin B: Cardiopulmonary responses to exercise in women with sickle cell anemia. Am J Respir Crit Care Med 2002, 165:1309-1316

48. Machado RF, Mack AK, Martyr S, Barnett C, Macarthur P, Sachdev V, Ernst I, Hunter LA, Coles WA, Nichols JP, Kato GJ, Gladwin MT: Severity of pulmonary hypertension during vasoocclusive pain crisis and exercise in patients with sickle cell disease. Br J Haematol 2007, 136:319-325 